\title{
Simulation of coal combustion by AUSM turbulence-chemistry char combustion model and a full two-fluid model
}

\author{
Yu Zhang ${ }^{\mathrm{a}, *}$, Xiao-Lin $\mathrm{Wei}^{\mathrm{a}}$, Li-Xing Zhou ${ }^{\mathrm{b}}$, Hong-Zhi Sheng ${ }^{\mathrm{a}}$ \\ ${ }^{a}$ Institute of Mechanics, Chinese Academy of Sciences, Beijing 100080, China \\ ${ }^{\mathrm{b}}$ The State Key Laboratory of Clean Coal Combustion, Tsinghua University, Beijing 100084, China
}

Received 28 July 2004; received in revised form 10 March 2005; accepted 10 March 2005

Available online 21 April 2005

\begin{abstract}
An algebraic unified second-order moment (AUSM) turbulence-chemistry model of char combustion is introduced in this paper, to calculate the effect of particle temperature fluctuation on char combustion. The AUSM model is used to simulate gas-particle flows, in coal combustion in a pulverized coal combustor, together with a full two-fluid model for reacting gas-particle flows and coal combustion, including the sub-models as the $k-\varepsilon-k_{\mathrm{p}}$ two-phase turbulence model, the EBU-Arrhenius volatile and CO combustion model, and the six-flux radiation model. A new method for calculating particle mass flow rate is also used in this model to correct particle outflow rate and mass flow rate for inside sections, which can obey the principle of mass conservation for the particle phase and can also speed up the iterating convergence of the computation procedure effectively. The simulation results indicate that, the AUSM char combustion model is more preferable to the old char combustion model, since the later totally eliminate the influence of particle temperature fluctuation on char combustion rate.
\end{abstract}

(C) 2005 Elsevier Ltd. All rights reserved.

Keywords: AUSM char combustion model; Particle temperature fluctuation; Particle mass outflow rate

\section{Introduction}

CFD has become a very powerful tool to simulate complex chemical multiphase in many processes, such as coal combustion, et al. In turbulence flow, it is very hard job for CFD to simulate the closure chemistry reaction rate. In commercial codes such as FLUENT, a simplified PDF model is used. Due to the approximation made in adopting the product of several single-variable PDF's instead of a joint PDF, when using this model to predict NO formation, the difference between prediction and experiment is rather large [1]. An earlier version of a second-order moment model was used to predict NO formation in coal combustion [2], and the predicted results have not yet been verified by experiment. However, this model has been used to simulate NO formation in methane-air combustion [3] and the NO concentration is significantly under-predicted due to the fact

\footnotetext{
* Corresponding author. Tel: +86 10 86595786; fax +86 1062619747.

E-mail address: yuzhang@imech.ac.cn (Y. Zhang).
}

0016-2361/\$ - see front matter (C 2005 Elsevier Ltd. All rights reserved. doi:10.1016/j.fuel.2005.03.010 that the approximation of $\mathrm{E} / \mathrm{RT} \ll 1$ made in the series expansion of the exponential function of temperature leads to the elimination of the higher-order terms, which cannot be neglected for E/RT $>5$ in the case of NO formation. In order to improve the second-order moment (SOM) models, a SOM-PDF model [4] and a unified SOM (USM) model [5] were proposed. These models are used to simulate methaneair combustion and NO formation and both of them have been well verified by experiment. The results show that the SOM-PDF and USM models are much better than the EBUArrhenius model, the simplified PDF model and the old version of the SOM model. For the coal combustion conditions, due to the complexity of the processes, an algebraic unified second-order moment (AUSM) turbulence-chemistry model for NO formation has also been proposed [6].

As more attention is focused on the chemical reaction details of the char combustion model [7], there are still no reports about the influence of particle turbulence on char combustion rate. In this paper, The E-E model is used to describe two-phase flow, which means that particle phase is also treated as a fluid phase and the Euler method is used to 
describe both two-phase movements. Since the particle phase is treated like a continuous phase, it has own turbulent kinetic energy, stress and so on. If there is two-phase chemical reaction flow, the particle phase should also have own temperature fluctuation. In this paper, a new AUSM turbulence chemistry reaction model of char combustion is proposed, which takes the particle temperature fluctuation into account. The simulation results indicate that, the model proposed in this paper is more reasonable than the old model.

In this paper a set of in-house procedures is used. In the gas phase CFD simulation, it is well known that, for the procedure to converge and produce the reasonable predicted results, the outflow rate must be corrected by the principle of mass conservation in the procedure. In this paper, as well as a real coal combustor simulation, an outflow rate correction method for the particle phase in a two-fluid model is also discussed.

\section{AUSM turbulence chemistry char combustion model}

\subsection{Particle temperature fluctuation}

Fig. 1 shows the particles at different times in the same places. The black points mean low temperature particles without char combustion, while the white points represent the high temperature particles with char combustion. Clearly, the particle temperatures at different times in the same place are likely to change and fluctuate because of char combustion. It can be shown by means of time average method that:

$\overline{T_{\mathrm{p}}(x)}=\frac{1}{T} \int_{t-T / 2}^{t+T / 2} T_{\mathrm{p}}(x, t) \mathrm{d} t$

$T_{\mathrm{p}}(x, t)=\overline{T_{\mathrm{p}}(x)}+T_{\mathrm{p}}^{\prime}(x, t)$

where $T$ is the time period, $T_{\mathrm{p}}$ is the instantaneous particle temperature, $\overline{T_{\mathrm{p}}}$ is the time averaged particle temperature. The instantaneous gas-particle chemical reaction rate can be expressed as follows:

$m=-\frac{1}{\beta} \pi d_{\mathrm{p}}^{2} \rho_{\mathrm{S}} Y_{\mathrm{O}_{2}} B \exp \left(-\frac{E}{R T_{\mathrm{p}}}\right)$

where the $\beta, B, E$ are the chemical reaction parameters, $d_{\mathrm{p}}$ is the particle diameter, $\rho_{\mathrm{s}}$ is the mean gas density at surface of

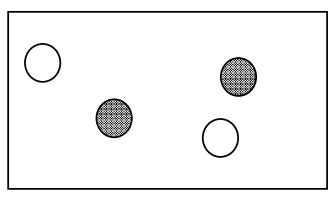

$\mathrm{t}$

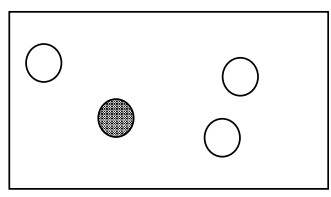

$\mathrm{t}+\mathrm{dt}$
Fig. 1. Particles at different Times $t$ and $t+\mathrm{d} t$. particle, and $Y_{\mathrm{O}_{2}}$ is the oxygen component of the reaction gas at the surface of particle. If the correlation of components is neglected, the time averaged multi-phase chemical reaction rate is as following:

$\dot{m}=-\frac{1}{\beta} \pi d_{\mathrm{p}}^{2} \rho_{\mathrm{S}} Y_{\mathrm{O}_{2}, \mathrm{~S}} B_{1} \overline{\exp \left(-\frac{E}{R T_{\mathrm{p}}}\right)}$

It can be seen that, in turbulent flow, there is still a closure problem of the turbulent multiphase chemical reaction rate which is explained in the reference [2].

\subsection{AUSM turbulence chemistry char combustion model}

Assuming that, there are three chemical reactions on the surface of char

$\mathrm{C}+\mathrm{O}_{2} \rightarrow \mathrm{CO}_{2}, \quad 2 \mathrm{C}+\mathrm{O}_{2} \rightarrow 2 \mathrm{CO}, \quad \mathrm{C}+\mathrm{CO}_{2} \rightarrow 2 \mathrm{CO}$

then

$$
\begin{aligned}
\dot{m}_{\mathrm{c}, \mathrm{p}}^{1}= & -\frac{1}{\beta_{\mathrm{c} 1}} \pi d_{\mathrm{p}}^{2} \rho_{\mathrm{S}} Y_{\mathrm{O}_{2}, \mathrm{~s}} B_{1} \times 0.5 \times\left(\exp \left(-\frac{E_{1}}{R\left(\overline{T_{\mathrm{p}}}+1 / 2 T_{\mathrm{p}}^{\prime}\right)}\right)\right. \\
& \left.+\exp \left(-\frac{E_{1}}{R\left(\overline{T_{p}}-1 / 2 T_{\mathrm{p}}^{\prime}\right)}\right)\right), \\
\dot{m}_{\mathrm{c}, \mathrm{p}}^{2}= & -\frac{1}{\beta_{\mathrm{c} 2}} \pi d_{\mathrm{p}}^{2} \rho_{\mathrm{S}} Y_{\mathrm{O}_{2}, \mathrm{~s}} B_{2} \times 0.5 \times\left(\exp \left(-\frac{E_{2}}{R\left(\overline{T_{\mathrm{p}}}+1 / 2 T_{\mathrm{p}}^{\prime}\right)}\right)\right. \\
& \left.+\exp \left(-\frac{E_{2}}{R\left(\overline{T_{\mathrm{p}}}-1 / 2 T_{\mathrm{p}}^{\prime}\right)}\right)\right), \\
\dot{m}_{\mathrm{c}, \mathrm{p}}^{3}= & -\frac{1}{\beta_{\mathrm{c} 3}} \pi d_{\mathrm{p}}^{2} \rho_{\mathrm{S}} Y_{\mathrm{CO}_{2}, \mathrm{~S}} B_{3} \times 0.5 \times\left(\exp \left(-\frac{E_{3}}{R\left(\overline{T_{\mathrm{p}}}+1 / 2 T_{\mathrm{p}}^{\prime}\right)}\right)\right. \\
& \left.+\exp \left(-\frac{E_{3}}{R\left(\overline{T_{\mathrm{p}}}-1 / 2 T_{\mathrm{p}}^{\prime}\right)}\right)\right) \\
T_{\mathrm{P}}^{\prime}= & \overline{T_{\mathrm{p}}} / \overline{T_{\mathrm{g}}} \times T_{\mathrm{g}}^{\prime}
\end{aligned}
$$

Formula (6) gives the AUSM model, which is proposed in this paper. $T_{\mathrm{P}}^{\prime}$ is the particle temperature fluctuation, $\overline{T_{\mathrm{p}}}$ is the mean particle temperature, $\overline{T_{\mathrm{g}}}$ means the gas mean temperature, and $T_{\mathrm{g}}^{\prime}$ represents the gas temperature fluctuation. There is a simple assumption that the ratio of particle temperature to gas temperature equals the ratio of particle temperature fluctuation to gas temperature fluctuation, so what $T_{\mathrm{P}}^{\prime}$ can be expressed by formula (7), and may avoid solving the particle temperature conservation equation.

Formula (8) gives the old char combustion model, from which it can be seen that, here the effect of particle temperature fluctuation on char chemical reaction rate is 
totally eliminated.

$$
\begin{aligned}
& \dot{m}_{\mathrm{c}, \mathrm{p}}^{1}=-\frac{1}{\beta_{\mathrm{c} 1}} \pi d_{\mathrm{p}}^{2} \rho_{\mathrm{S}} Y_{\mathrm{O}_{2}, \mathrm{~S}} B_{1} \exp \left(-\frac{E_{1}}{R \overline{T_{\mathrm{p}}}}\right), \\
& \dot{m}_{\mathrm{c}, \mathrm{p}}^{2}=-\frac{1}{\beta_{\mathrm{c} 2}} \pi d_{\mathrm{p}}^{2} \rho_{\mathrm{S}} Y_{\mathrm{O}_{2}, \mathrm{~S}} B_{2} \exp \left(-\frac{E_{2}}{R \overline{T_{\mathrm{p}}}}\right), \\
& \dot{m}_{\mathrm{c}, \mathrm{p}}^{3}=-\frac{1}{\beta_{\mathrm{c} 3}} \pi d_{\mathrm{p}}^{2} \rho_{\mathrm{S}} Y_{\mathrm{CO}_{2}, \mathrm{~S}} B_{3} \exp \left(-\frac{E_{3}}{R \overline{T_{\mathrm{p}}}}\right)
\end{aligned}
$$

\section{The full two-fluid model for reacting gas-particle flows and coal combustion}

For the comprehensive modelling of reacting gasparticle flows and coal combustion, a full two-fluid model [6] is used. The continuity, momentum, energy and turbulent kinetic energy equations for gas phase and particle phase are derived and solved in Eulerian coordinates. The sub-models are: $k-\varepsilon-k_{\mathrm{p}}$ two-phase turbulence model, EBU-Arrhenius combustion model, six-flux radiation model: and two-equation model of coal devolatilization. The detailed description of this comprehensive model can be found the Ref. [6]. The AUSM turbulence-chemistry model for char formation is incorporated into the comprehensive model.

The basic equations of 3D turbulent two-phase reacting flows and coal combustion can be expressed in the following generalized form:

Gas-phase equations:

$$
\begin{gathered}
\frac{\partial}{\partial x}(\rho u \varphi)+\frac{\partial}{r \partial r}(r \rho v \varphi)+\frac{\partial}{r \partial \theta}(\rho w \varphi)=\frac{\partial}{\partial x}\left(\Gamma_{\varphi} \frac{\partial \varphi}{\partial x}\right) \\
+\frac{\partial}{r \partial r}\left(r \Gamma_{\varphi} \frac{\partial \varphi}{\partial r}\right)+\frac{\partial}{r^{2} \partial \theta}\left(\Gamma_{\varphi} \frac{\partial \varphi}{\partial \theta}\right)+S_{\varphi}+S_{\varphi \mathrm{p}}
\end{gathered}
$$

Particle-phase equations:

$$
\begin{aligned}
& \frac{\partial}{\partial x}\left(\rho_{\mathrm{p}} u_{\mathrm{p}} \varphi_{\mathrm{p}}\right)+\frac{\partial}{r \partial r}\left(r \rho_{\mathrm{p}} v_{\mathrm{p}} \varphi_{\mathrm{p}}\right)+\frac{\partial}{r \partial \theta}\left(\rho_{\mathrm{p}} w_{\mathrm{p}} \varphi_{\mathrm{p}}\right)=\frac{\partial}{\partial x}\left(\Gamma_{\varphi \mathrm{p}} \frac{\partial \varphi_{\mathrm{p}}}{\partial x}\right) \\
& +\frac{\partial}{r \partial r}\left(r \Gamma_{\varphi \mathrm{p}} \frac{\partial \varphi_{\mathrm{p}}}{\partial r}\right)+\frac{\partial}{r^{2} \partial \theta}\left(\Gamma_{\varphi \mathrm{p}} \frac{\partial \varphi_{\mathrm{p}}}{\partial \theta}\right)+S_{\varphi \mathrm{p}}+S_{\varphi \mathrm{pg}}
\end{aligned}
$$

where ( and $\left(_{\mathrm{p}}\right.$ are the generalized independent variables, and $S_{,}, S_{(\mathrm{p}}$ and $S_{(\mathrm{pg}}$ are the source items. The meanings of these variables and terms are given in the Ref. [6].

The boundary conditions for the gas phase and particle phase are specified as in usual treatment, fully developed flow conditions at the exit; symmetrical conditions at the axis; non-slip condition for the gas velocity at the wall; and the wall function approximation is used for near-wall grid nodes. The particle-phase conditions at the wall are: Zero Normal Mean Velocity (ZNMV) and zero gradients of other variables

\section{Mass flow rate correction method of particle phase in two-fluid model}

In this paper a set of in-house procedures is used to simulate multiphase flow based on the two-fluid model. In the pure gas flow simulation, it is will known that the gas mass flow rate must be corrected by the principle of mass conservation: what is the basic requirement of the SIMPLE method [9]. In the two-phase flow simulation, the gas phase mass flow rate still needs to be corrected, which is the same as that for pure gas flow simulation, and can be expressed as follows:

$U(\mathrm{LP} 1, J, K)=U(L, J, K) \times \operatorname{SUMGASIN} / \operatorname{MASSG}(L)$

$U$ is the main flow velocity, SUMGASIN is the inlet mass flow, LP1 means outflow boundary section. $L$ represents nearest section to the outlet. MASSG is the mass flow at different sections, and can be expressed as follows:

$$
\begin{aligned}
\operatorname{MASSG}(I)= & 0.5 \times(\operatorname{RHO}(I, J, K)+\operatorname{RHO}(I-1, J, K)) \\
& \times U(I, J, K) \times A
\end{aligned}
$$

In formula (12), RHO means the density of the gas. $A$ is the sectional area of the combustor. The outflow rate correction is the basic requirement of the SIMPLE method. Since mass flow at every section is corrected, iteration can converge quickly, and it is often used in real simulation work.

In the multiphase flow simulation, if the two-fluid model used, the particle is treated as a continuous phase. The question here arisen as to whatever the particle mass flow rate needed to be corrected or not? What is the most reasonable method? If use gas mass flow rate correcting method is used for particle phase, formulae (11) and (12) can be recasted as follows:

$\mathrm{UP}(\mathrm{LP} 1, J, K)=\mathrm{UP}(L, J, K) \times \operatorname{SUMGASINP} / \operatorname{MASSP}(L)$

$$
\operatorname{MASSP}(I)=0.5 \times(\operatorname{RHOP}(I, J, K)+\operatorname{RHOP}(I-1, J, K))
$$$$
\times \mathrm{UP}(I, J, K) \times A
$$

UP means main flow velocity of particle phase, MASSP is particle mass flow rate at different sections, RHOP is particle concentration. The method, the so called Method 1, is described by formulae (12) and (14) to calculate mass flow rate.

Unfortunately, if the above method is used to correct the particle mass flow rate at different sections, generally speaking, the iteration will not converge. So, many researchers considered that particle mass flow rate cannot be corrected.

Figs. 2 and 3 show the section gas and particle mass flow rates along the reactor height without any chemical reactions (Details of experimental work are introduced in 


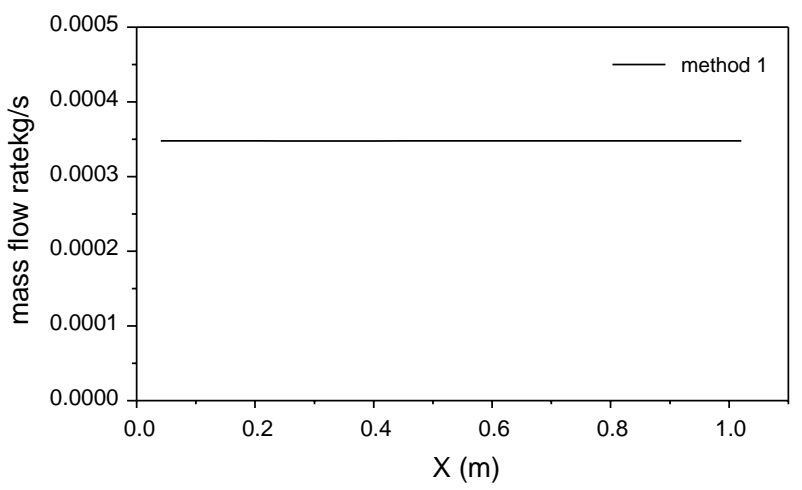

Fig. 2. Gas mass flow rate along the reactor height.

the next section). Fig. 2 indicates that, along the reactor height the gas flow rate is not changed, which is considered. For particles, the mass flow rate calculated by method 1 increases at first and then decreases along the reactor height (Fig. 3). Apparently, this breaks the mass conservation rule. If this curve is used to correct particle mass flow rate, the iteration will not converge.

Recast formula (14) is

$$
\begin{aligned}
\operatorname{MASSP}(I)= & \operatorname{MASSP}(I)+\mathrm{UP}(I, J, K) \\
& \times \operatorname{RHOP}(I-1, J, K) \times A_{j k} \quad(\mathrm{UP}(I, J, K)>0)
\end{aligned}
$$

when

$$
\begin{aligned}
\operatorname{MASSP}(I)= & \operatorname{MASSP}(I)+\mathrm{UP}(I, J, K) \times \operatorname{RHOP}(I, J, K) \times A_{\mathrm{jk}} \\
& (\mathrm{UP}(I, J, K)<0)
\end{aligned}
$$

The method to calculate the mass flow rate by formula (5) called method 2, gives reasonable results. The particle mass flow rate is not great changed along the reactor height. When using calculated results to correct particle outflow rate or mass flow rate at inside sections, the iteration will converge.

The main difference between method 1 and method 2 is the way in which particle concentration is treated. The former uses the central difference scheme while the later takes the up-wind difference scheme. Indeed, the particle

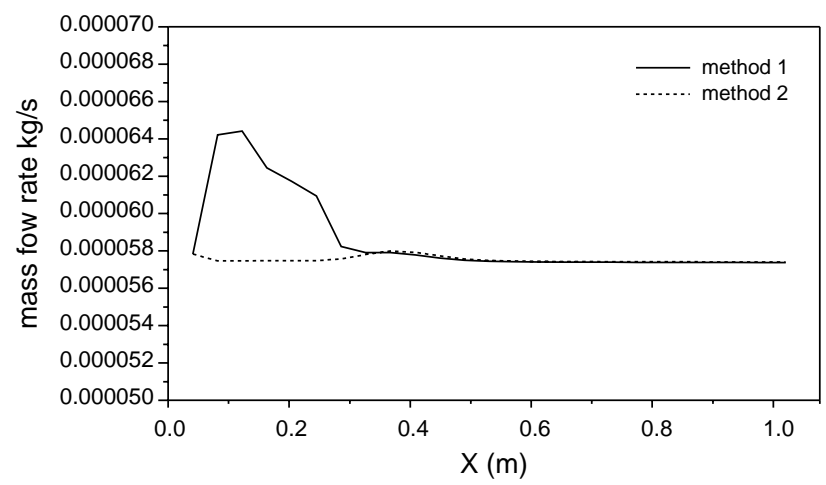

Fig. 3. Particle mass flow rate along the reactor height. concentration continuum equation essentially differs form the gas continuum equation. The gas continuum equation is converted to a pressure correction equation, different from other conservation equations characterized by a central difference scheme. The particle concentration equation is a normal conservation equation, and is characterized by an up-wind difference scheme. For this reason, the methods to calculate section mass flow rate of gas and particles are different, and using method 1 to calculate particle mass flow rate will lead to the wrong results.

It worth mentioning that, the particle phase mass flow rate correction has a different meaning from the gas phase mass flow rate correction. For the gas phase, the outflow rate correction is indispensable, which is an essential requirement of the SIMPLE method. An inside mass flow rates correction at different sections is just used to save calculation time. For the particle phase, both outflow rate correction and inside mass flow rate correction are dispensable, being used only for saving calculation time. Therefore, even if the mass flow rate correction is not used for the particle phase, the procedure run smoothly, but converges slowly.

\section{Experimental section}

The trial tests were conducted in an entrained flow combustion reactor (EFCR) (see Fig. 4). The electrically heated reactor has five regulated heating zones. The carrying air with pulverized coal enters the burner center,

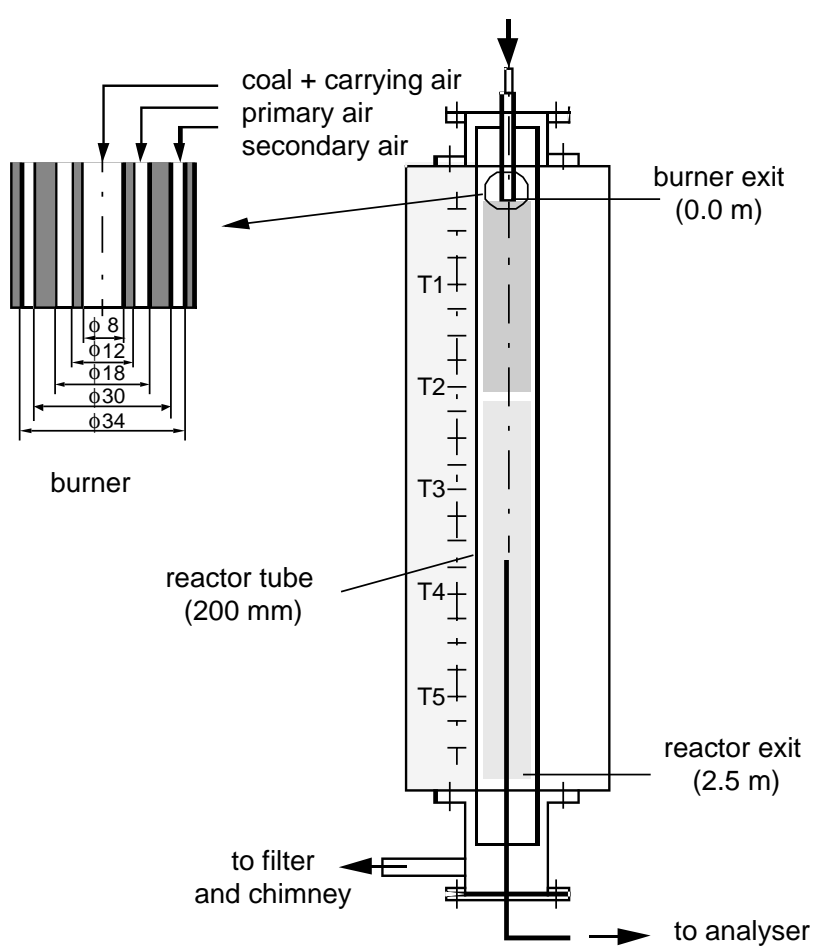

Fig. 4. Schematic of the coal combustor. 
Table 1

Parameters of the basic calculation

\begin{tabular}{lll}
\hline Parameters & Units & Values \\
\hline Coal mass flow & $\mathrm{kg} / \mathrm{h}$ & 1.0 \\
Wall temperature & ${ }^{\circ} \mathrm{C}$ & 1250 \\
Volume flow of coal carrying air & $\mathrm{Nm}^{3} / \mathrm{h}$ & 1.5 \\
Temperature of coal carrying air & ${ }^{\circ} \mathrm{C}$ & 200 \\
Primary air + secondary air & $\mathrm{Nm}^{3} / \mathrm{h}$ & 8.0 \\
Primary air:secondary air & - & $1: 2$ \\
Temperature of primary air & ${ }^{\circ} \mathrm{C}$ & 250 \\
Temperature of secondary air & ${ }^{\circ} \mathrm{C}$ & 350 \\
Mean diameter of particle & $\mu \mathrm{m}$ & $16,52,160,350$ \\
& $\%$ & $30,35,25,10$ \\
\hline
\end{tabular}

Table 2

Coal analysis data of coal type 1

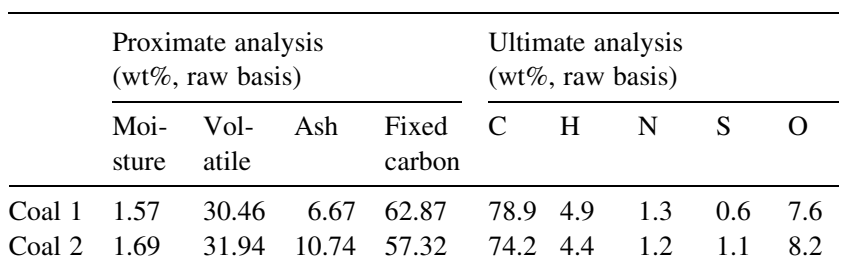

surrounded by the primary air and the secondary air. A gravimetric screw conveyor supplies a constant coalfeeding rate. The furnace (ceramic tube) has a length of $2.5 \mathrm{~m}$ and an internal diameter of $200 \mathrm{~mm}$ [8].
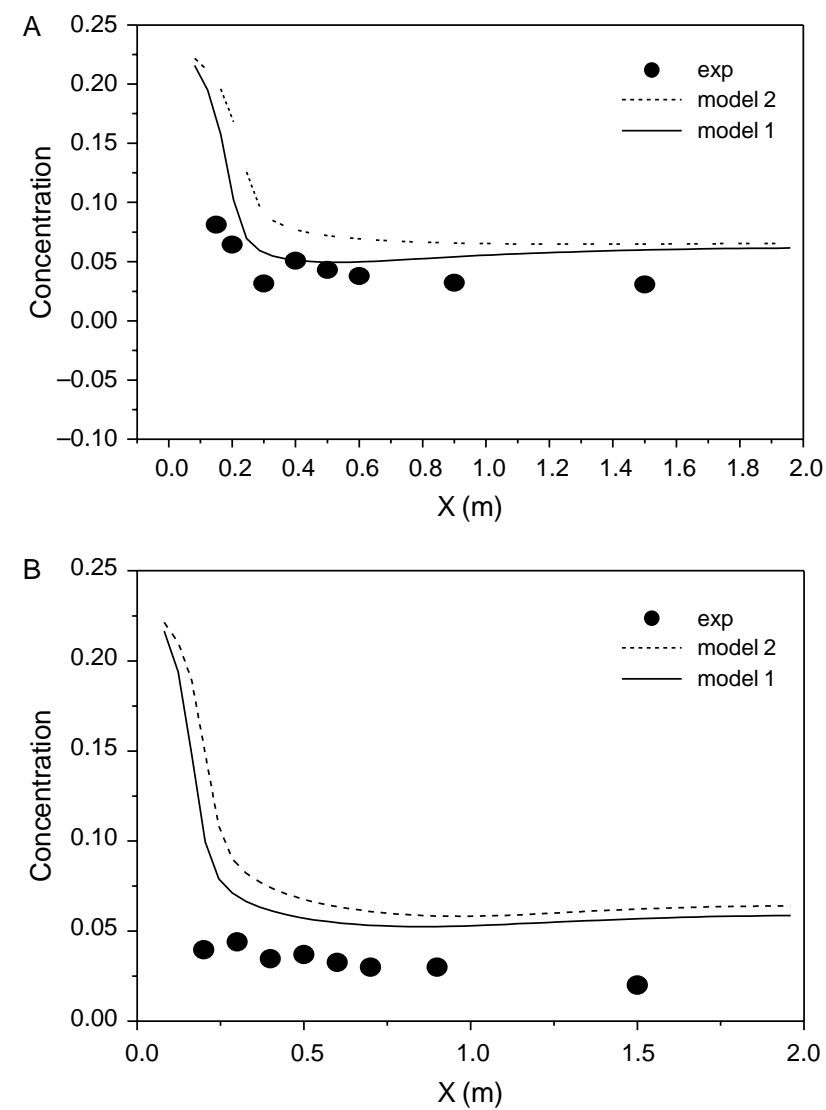

Fig. 5. The $\mathrm{O}_{2}$ concentration along the reactor height $(\mathrm{A}-\operatorname{coal} 1 \mathrm{~B}-\mathrm{coal} 2)$.
Table 1 gives the parameters of the basic calculation. Table 2 gives the two bituminous and analysis data. A set of in-house CFD procedure is used to simulate coal combustion and NO formation, A non-uniform staggered grid which nodes of $50 \times 30 \times 7$ are used. Running a example on a Pentium-4-2.0G-personal computer takes about 4-5 days.

\section{Results and discussion}

Fig. 5 gives the indicated and experimental oxygen concentration result for different coals. Model 1 means the AUSM turbulent char combustion model, while the model 2 is the old char combustion model. From Fig. 5, it can be seen that, the predicted result of model 1 is more accurate compared with model 2, From while the result is higher than the experimental result. Fig. 6 shows the carbon dioxide concentration for different coals. Apparently, the predicted result of model 1 is better than that of model 2, which is lower than the experimental data. Both Figs. 5 and 6 indicate that, for the sake of eleminating the effect of fluctuations in the particle temperature the old model underestimates the char combustion rate, so its predicted oxygen result is higher than in model 1 , while the predicted carbon dioxide result is lower. The AUSM model takes the particle temperature fluctuation into account most
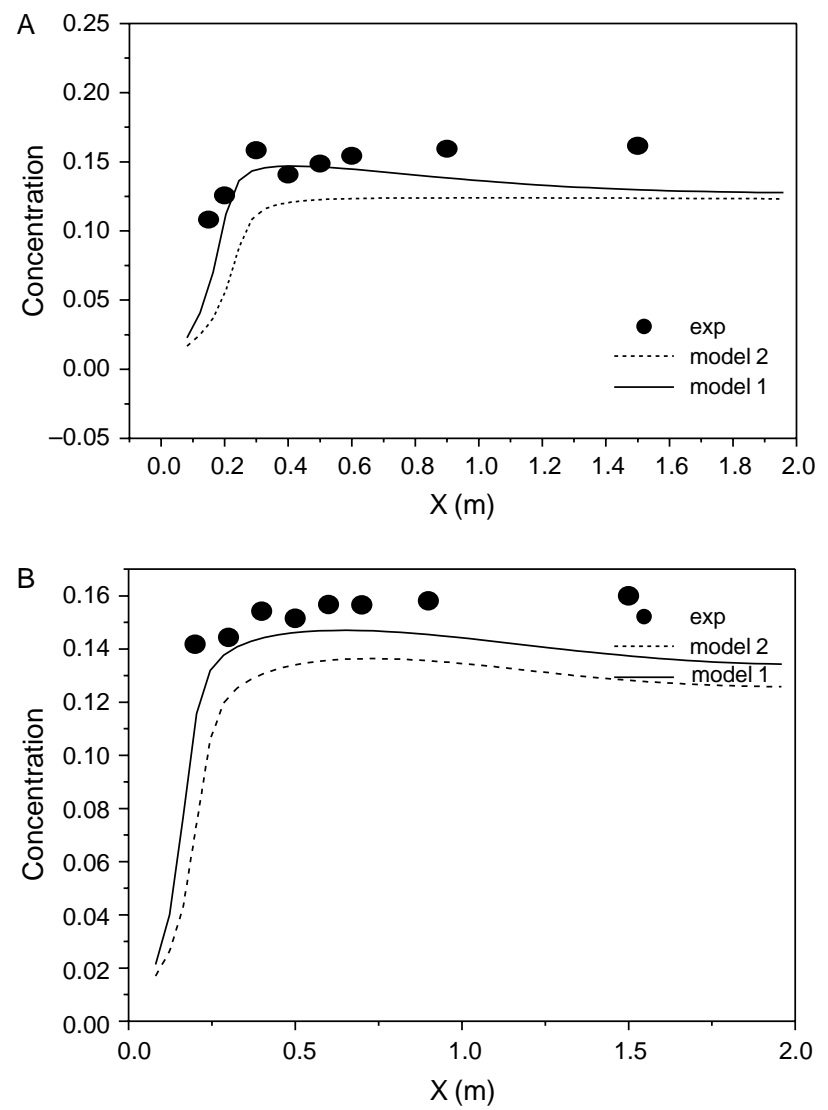

Fig. 6. The $\mathrm{CO}_{2}$ concentration along the reactor height $(\mathrm{A}-\operatorname{coal} 1 \mathrm{~B}-\operatorname{coal} 2)$. 

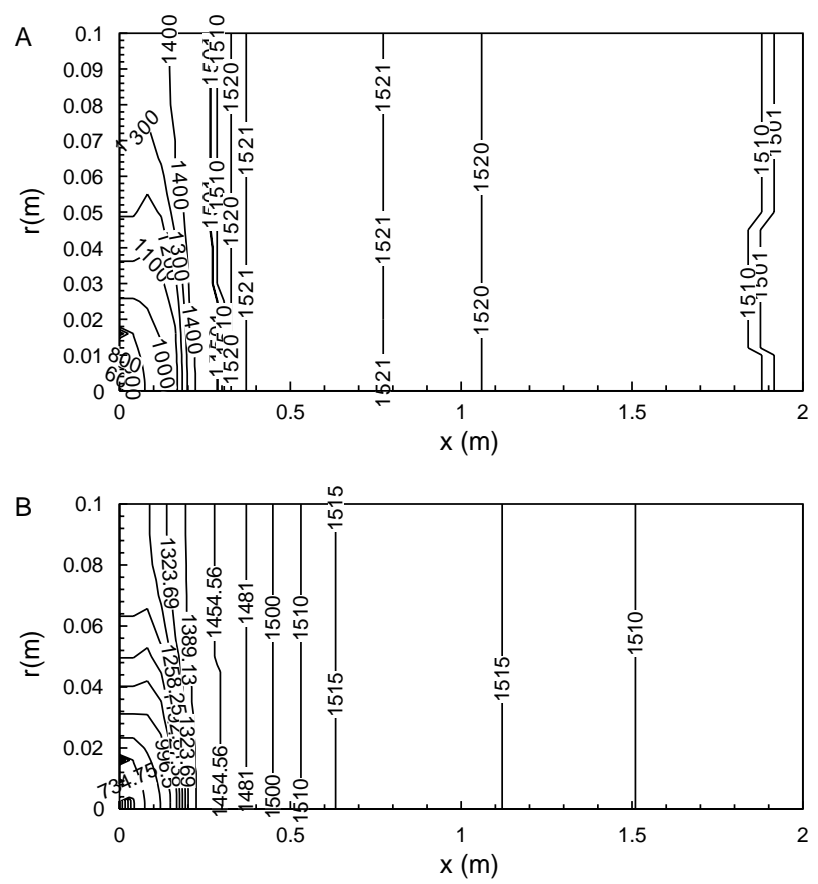

Fig. 7. The particle temperature map (A—coal $1 \mathrm{~B}-\mathrm{coal} 2)$.
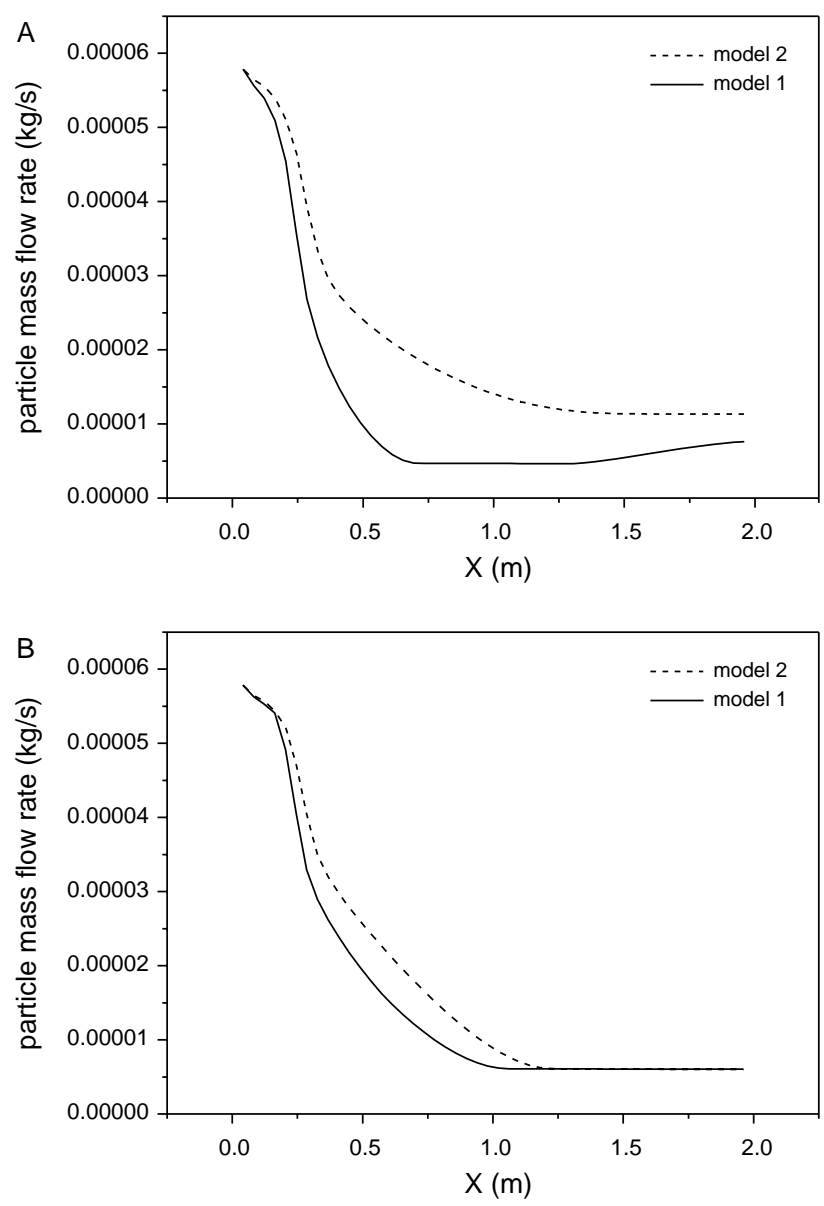

Fig. 8. The coal mass flow rate along the reactor height (A—coal $1 \mathrm{~B}-\mathrm{coal} 2)$. reasonable, so its predicted results are better. From Figs. 5 and 6 can be seen that, in the inlet region, the difference between the predicted results and experimental results is comparatively large. The reason for this might be a measurement error. Near the inlet of the reactor, it is hard to keep the analysis tube at the exact central position in the inlet and the measurement data become very 'sensitive' to the position of the probe.

Fig. 7 gives the particle temperature map; it can be seen that in the inlet region the particle temperature rises very rapidly. Fig. 8 shows the particle mass flow rate along the reactor height; it can be seen that the particle reaction rate predicted as AUSM is higher than that of old model. In other words, particle temperature fluctuation will enhance the particle combustion process.

\section{Conclusions}

1. The old char combustion model totally eliminates the influence of particle temperature fluctuation on char combustion rate. Its predicted oxygen concentration is higher than the experimental data while the predicted carbon dioxide level is lower than experimental.

2. The AUSM turbulence char combustion model takes the particle temperature fluctuation into account will, both the predicted oxygen and carbon dioxide are better than the predicted results by the old char combustion model, especially in the inlet region, where the particle temperature fluctuation is very high.

3. The gas mass outflow rate correction should be considered in two-fluid model simulation. For particle phase, the outflow rate correction is dispensable and may be used only to save calculation time. It should be noted that, the mass flow rate correction methods for gas and particle are essential different.

\section{Acknowledgements}

Financial Support from the Chinese Special Funds for Major State Basic Research Projects (G1999022102) and National Natural Science Foundation of China (No.50376068) is acknowledged.

\section{References}

[1] Zhou LX. Advances in numerical modeling of turbulent reaction of NOx formation. Adv Mech (China) 2000;30:77-82.

[2] Zhou LX, Guo YC, Lin WY. Two-fluid models for simulation reacting gas-particle flows, coal combustion and $\mathrm{NO}_{\mathrm{x}}$ Formation. Combust Sci Technol 2000;(150):161-80.

[3] Liao CM, Liu ZN, Zheng XQ, Liu CQ. NOx prediction in 3D turbulent diffusion flames by using implicit multi-grid methods. Combust Sci Technol 1996;119:219-60. 
[4] Zhou LX, Chen XL, Zheng CG, Yin J. Second-order moment turbulence-chemistry models for simulating NOx formation in gas combustion. Fuel 2000;79:1289-301.

[5] Zhou LX, Chen XL, Zheng CG, Yin J. Second-order moment turbulence-chemistry models for simulating NOx formation in gas combustion. Fuel 2000;79:1289-301.

[6] Zhou LX, Zhang Y, Zhang J. Simulation of swirling coal combustion using a full two-fluid model and an AUSM turbulence-chemistry model. Fuel 2003;82:1001-7.
[7] Eaton AM, Smoot LD, Hill SC, Eatough CN. Coponents, formulations, solutions, evaluation, and application of comprehensive combustion models. Prog Energy Combust Sci 1999;25:387-436.

[8] Wei X, Han X, Schnell U, Maier J, Woerner H, Hein KRG. The effect of $\mathrm{HCl}$ and $\mathrm{SO}_{2}$ on $\mathrm{NO}_{x}$ formation in coal flames. Energy Fuels 2003 17(5):1392-8.

[9] Patankar SV, Patankar DB. A calculation procedure for heat, mass and momentum transfer in three-dimensional parabolic flows. Int $\mathrm{J}$ Heat Mass Transfer 1972;15:1787-806. 